\title{
San Bernardo, Santa Muerte o San La Muerte: brujos, brujeados y santos en la provincia de Imbabura
}

\author{
Esthela Alfonsina Andrade Ortega ${ }^{1}$
}

\begin{abstract}
RESUMEN
EL TEMA DE LA BRUJERÍA ES UN TEMA FASCINANTE, TANTO PARA HISTORIADORES, ANTROPÓLOGOS Y OTROS CIENTÍFICOS SOCIALES COMO PARA LA GENTE COMÚN. EN LA PROVINCIA DE IMBABURA, LA BRUJERÍA ES ENTENDIDA COMO LA ALTERACIÓN DE LA ARMONÍA A TRAVÉS DE LA MANIPULACIÓN DE LOS EVENTOS POR MEDIO DE UNA SERIE DE RITUALES; ASÍ, CUALQUIER DESGRACIA (ENFERMEDAD, DESEMPLEO, DIVORCIOS) ES VISTA COMO PRODUCTO DE ELLA. EL OBJETIVO DE ESTE ARTÍCULO ES DESCRIBIR EL FENÓMENO DE LA BRUJERÍA EN LA PROVINCIA DE IMBABURA, PRINCIPALMENTE LA RElacionada con SAN BERNARDo, QUIEN ES El SANTO PRINCIPAL DE LOS BRUJOS DE LA PROVINCIA. ESTE SANTO ES REPRESENTADO COMO UN ESQUELETO CON MANTO Y GUADAÑA. Su CULTO GUARDA CIERTAS SIMILITUDES, PERO TAMBIÉN varias diferencias, con el culto a la Santa Muerte en México y San La Muerte en Uruguay y Argentina. Es así que mientras el culto a la SANTa Muerte Crece en los países antes mencionados, el culto a San Bernardo

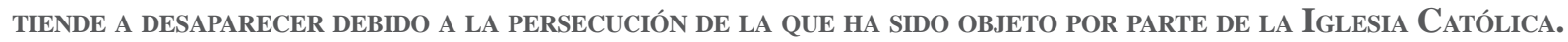

Palabras clave: brujería-San Bernardo-muerte-culto.

\section{ABSTRACT}

THE SUBJECT OF WITCHCRAFT IS FASCINATING FOR HISTORIANS, ANTHROPOLOGISTS AND OTHER SOCIAL SCIENTISTS AS ORDINARY PEOPLE. IN IMBABURA, WITCHCRAFT IS DEFINED AS THE DISRUPTION OF HARMONY THROUGH THE MANIPULATION OF EVENTS IN A SERIES OF RITUALS, AND ANY MISFORTUNE (SICKNESS, UNEMPLOYMENT, DIVORCE) ARE SEEN AS A RESULT OF IT. THE ISSUE OF THIS PAPER IS TO DESCRIBE THE PHENOMENON OF WITCHCRAFT IN IMbabURA MAINLY ABOUT ST. BERNARD, WHO IS THE PRINCIPAL SAINT OF WITCHES IN THIS PLACE. THIS SAINT IS DEPICTED AS A SKELETON WITH ROBE AND SCYTHE. THE CUlt OF THIS SAINT HAS SOME SIMILARITIES BUT ALSO SOME DIFFERENCES WITH THE CULT OF SANTA Muerte in Mexico and San La Muerte in Uruguay and Argentina. So while the Santa Muerte cult grows IN THE COUNTRIES MENTIONED ABOVE, THE CULT OF SAINT BERNARD TENDS TO DISAPPEAR BECAUSE OF THE PERSECUTION Which has been subjected by the Catholic Church.

KeYWORDS: WITCHCRAFT-SAN BERNARDO-DEATH-CULT.

1 Licenciada en Antropología. Magíster en Relaciones Internacionales. Investigadora titular en la Escuela Superior Politécnica Ecológica Amazónica, Tena-Napo, Ecuador, morticiaandrade76@hotmail.com 


\section{Introducción}

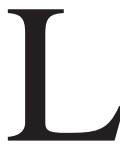

a brujería es un tema bastante estudiado por la antropología a nivel mundial; así existen trabajos como los de Evans-Pritchard (1976), Sharon (1980), Malinowski (1993) y otros. En el caso del Ecuador hay aportes como el de Fericgla (1998) y Morales (2011) en la ciudad de Mira, población conocida como hogar de las “voladoras” es decir de las brujas con escoba, tal como las que aparecen en los cuentos de hadas.

El significado del concepto de brujería representa una labor compleja pues, en las comunidades andinas principalmente entre los blanco-mestizos, se confunde la brujería con la práctica y rituales de la etnomedicina y el chamanismo. Así es cómo se les llama comúnmente brujos a todos los médicos tradicionales incluidos yachaks y shamanes. Yachak viene del quichua yachana (saber) significa el que sabe el que conoce (sabio), su etimología es similar a la shamán termino que llega a través del manchú-tungú y llega al vocabulario etnológico a través del ruso. La palabra tungú original de saman (xaman) de deriva del verbo scha-“saber”, por lo qué shamán significa alguien que sabe, que conoce (sabio)

Para lo referente a este estudio, he definido como brujo a aquel individuo que utiliza diversos métodos “mágico-religiosos” para ocasionar un daño físico en otro individuo por iniciativa propia o por pedido de un tercero, a cambio de dinero, bienes, etc., también por envidia o venganza; por lo tanto, se definirá brujería como el conjunto de métodos empleados con este fin.

La presente investigación busca hacer un acercamiento a la práctica de la brujería dentro de la provincia de Imbabura y, principalmente, a la referida a San Bernardo. Esta investigación la inicié en el año 2001 como parte de la investigación de mi tesis de licenciatura, sin embargo lo fascinante del tema me llevó a continuar mis investigaciones hasta el presente.

\section{El santo de los brujos}

La brujería en la provincia de Imbabura tiene como santo principal a San Bernardo que para los imbabureños es la representación de la muerte. "Es un "santo bravo" quien chupa la sangre del entregado y come su corazón, con lo cual la persona empieza a adelgazar, flaquear y se va secando hasta que finalmente muere” (Mazzáfero, sf: 288).

Este santo es representado como un esqueleto que viste un manto franciscano y más regularmente un manto negro portando una guadaña en la mano. Las imágenes pueden ser en madera o en yeso. Su representación es similar a la de la Santa Muerte de México o San La Muerte de Uruguay y Argentina; según Elsa Malvido (2005: 22) "nuestra esquelética muerte ya había sido bautizada y uncida por algunos grupos, como San Pascual Rey, Justo Juez o Presagiadora, en tanto que hoy se le llama San La Muerte, La Santísima, San Bernardo, San Pascualito Bailón, La Blanca, Niña o Hermana Blanca”. Lo que permite concluir que se trata del mismo santo.

En la provincia de Imbabura, se comenta que cuando una persona va a morir, a veces, aparece San Bernardo para llevarle. El algunos casos cuando uno de los brujos que le rinde culto está próximo a morir se dice que el santo "ya mismito viene" para llevarse tanto su cuerpo como su espíritu dentro de una carreta envuelta en fuego (carroza). Pues, a principios del siglo XX en la ciudad de Ibarra existía una bruja llamada Josefa muy conocida por hacer daño mediante San Bernardo. Cuando falleció le hicieron el tradicional velorio de tres días, sin embargo a la media noche del segundo día un viento fuerte abre la puerta de la sala donde se realizaba la velación apagando las velas con las que se alumbraban. Los asustados acompañantes salen a la calle en donde observan una carroza envuelta en fuego, conducida por San Bernardo, y en cuyo interior iba la bruja Josefa, atrás de la carroza seguía una procesión de varias personas vestidas 
de amarillo. Cuando llega la mañana, se encuentra al interior de la sala a varias personas que botaban espuma por la boca y el ataúd vacío. (Testimonio de Amalia Vaca, 96 años de edad).

De acuerdo a grupos devotos de la Santa Muerte, su culto se inicia a mediados del Siglo XIX en Veracruz, donde la muerte visitó en sueños a un chamán a quien le ordena difundir su culto por todo México y otros países entre los que se encuentra el Ecuador. Hay que tomar en cuenta, que los pueblos mesoamericanos ya rendían culto a la muerte, desde mucho antes de la llegada de los españoles, por lo que el culto al que se refieren sus devotos es a la variante de este culto precolombino, que conocemos en la actualidad.

Según Araujo, Peña, (2006: 1) el culto a la muerte fue combatido fuertemente por la Iglesia Católica en su afán de colonización y evangelización de los territorios españoles, pero fracasó en su intento y es así que:

“La colonización española logró disminuir el culto a la muerte, pero no erradicarlo, de manera que permaneció oculto hasta el siglo XIX, cuando ocurrió un resurgimiento en su devoción. Al principio del ciclo pasado diferentes personas, entre ellas católicas, mandaron a quemar toda imagen de la Santa Muerte en América, principalmente Centro y Sudamérica, para acabar con dicho culto”.

\section{Brujería en la provincia de Imbabura}

Sabemos por los cronistas que, para la época colonial, la brujería en América del Sur se encontraba bastante extendida en la sociedad andina. Pues se dice que: "La cantidad de hechiceros aumentó considerablemente y Polo de Ondegardo (Gobernador del Cuzco a mediados del siglo XVI) atribuye este fenómeno a la extensión general de la indigencia en las comunidades coloniales" (Cfr. en Sharon, 1980: 43).

Lo cierto es que, para principios del siglo XX, la brujería con ayuda de San Bernardo ya era conocida y se encontraba extendida en toda la provincia de Imbabura, con una diferencia respecto al culto en México y Uruguay, donde no se oculta su devoción y es un santo dual, es decir, se le rinde culto tanto con fines benéficos como maléficos. En Imbabura, es un santo maléfico y su culto es secreto. Una similitud entre los dos cultos se refiere a que este santo toma la vida de sus devotos en caso que estos no cumplan con el pago (penitencia, ofrenda u otro) por los favores recibidos.

A este santo se lo puede encontrar en algunas iglesias de Imbabura principalmente de Ibarra y Otavalo; sin embargo, debido a la persecución de la que ha sido objeto, cada vez son menos los lugares dónde se rinde el culto a este santo. Según varios informantes, a este santo se lo oculta tras el altar mayor, en la sacristía o en el campanario de la iglesia.

Actualmente, también, se lo puede encontrar en casas particulares (tal como a San Gonzalo de Riobamba otro santo empleado por los brujos), ya que conseguir la imagen del santo tallado en madera se lo puede hacer en varias tiendas de artesanías de San Antonio de Ibarra, parroquia urbana conocida por sus tallados artesanales, así como por la presencia de varios grupos denominados “satánicos” y bandas de rock.

\section{El robo de la pisada (hacer el mal)}

La forma más común de hacer brujería en las comunidades campesinas y rurales de Imbabura es el robo de la pisada. Para esto la persona que va ha hacer el daño, sigue a la victima para poder recoger la pisada (tomar la tierra que ha pisado y colocarla en una funda) sin que esta se dé cuenta. Con esta tierra, acude donde algún brujo, quien toma la tierra recogida y pregunta qué tipo de mal se espera lograr. Con esta información, el brujo procederá a realizar algún ritual en el cual convocará a varios espíritus, para posteriormente colocar en el interior de la funda una 


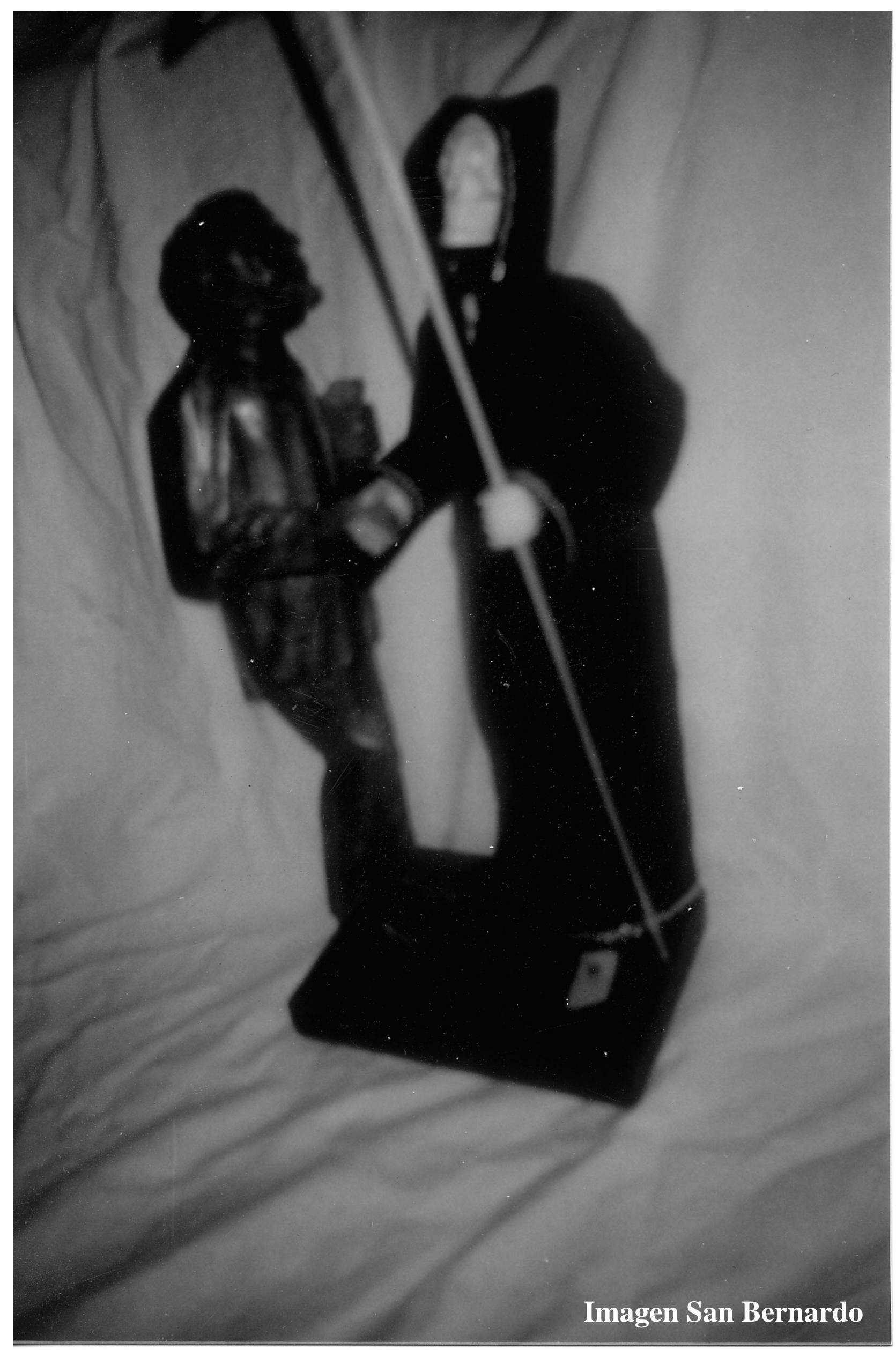


vela que representa el cuerpo de la persona y escribir en un papel preferentemente con la sangre de quién desea hacer el mal (aunque actualmente no es tan común) el nombre de la víctima, su victimario y el daño que se espera hacer. Normalmente el papel irá escrito en estos términos: "San Bernardo yo te pido que fulano(a) de tal se (enferme, le abandone su esposo(a), etc.) Tu devoto NN” (Andrade, 2004:67).

Luego de este sencillo ritual, el brujo acude con la pisada y el papel donde el sacristán de la iglesia y le pide que ponga esto bajo de San Bernardo; el precio que cobra el sacristán no es fijo, pero actualmente fluctúa entre los 5 y 10 dólares; cuando la víctima acude a retirar el papel con su nombre o que le borren del cuaderno, según sea el caso, el sacristán le cobra dependiendo del mal deseado. En ocasiones, la cantidad de dinero solicitada por el sacristán es tan alta que la persona debe hacer préstamos bancarios o con chulqueros para poder sacar la pisada.

En otros casos se roba la pisada del individuo y, con ayuda de un brujo, se lo entierra en uno o tres cementerios, para que, de esta manera, sea más difícil la curación de la persona y que ésta muera de algún mal inexplicable dentro de la medicina científica formal e, incluso, de la medicina tradicional.

El tiempo que tiene la víctima, de sacar la pisada y limpiarse del mal, es limitado ya que la vela al interior de la funda, con la tierra de la pisada, se irá consumiendo y cuando termine de hacerlo, la persona muere.

Se dan casos en los cuales seudo pitonisos (as) hacen creer a alguna persona que acude a su consulta que ha sido brujeados a través de este santo. Entonces, cuando la persona acude a retirar el papel, en la mayoría de los casos no lo encuentra. El sacristán o el custodio de San Bernardo, disimuladamente, le averigua el nombre y qué mal le aqueja; inmediatamente dice que el nombre debe estar en el cuaderno y acude a sacarle de la sacristía, momento que es utilizado para escribirlos en el cuaderno y, de esta manera, se aprovecha de los dólares de la víctima para borrarle; este dinero generalmente se reparten con las pitonisas.

\section{Diversas formas de brujear}

En los sectores urbanos, el robo de la pisada reviste varias dificultades, por lo que se acude a otras artimañas para proceder a brujear a las personas. Así, se corta un mechón de cabello de la víctima o se roba disimuladamente, un pañuelo, un trozo de ropa, una joya u otro; incluso se puede utilizar la foto de la víctima y se acude donde el brujo para seguir el mismo procedimiento que en el robo de la pisada. En algunos casos, se roba o pide prestada una prenda a la víctima, la que será curada por el brujo en nombre de San Bernardo, de manera que, cuando ésta sea usada, el maleficio pueda surtir efecto. Se mantiene, en todos los casos, el procedimiento de escribir en un papel los nombres y el mal que se desea hacer, para colocarlo debajo de San Bernardo y lograr que la brujería tenga mayor fuerza.

\section{El “diagnóstico"}

"Las creencias en la brujería son dramas que incluyen, en sus fases de desarrollo, el recurso a adivinos que determinan la culpa y establecen la inocencia...la variedad de estas creencias está generada en alguna medida por la variedad de circunstancias concretas que "explican” místicamente el infortunio” (Turner, 1981: 131).

De acuerdo con los informantes, existen varias formas de conocer si una persona ha sido brujeada; sin embargo, los procedimientos más comunes son los siguientes:

El tabaco: el yachak procede a encender un cigarrillo o un puro y soplar el humo por todo el cuerpo del paciente; si durante este procedimiento el centro del tabaco adquiere la textura y 
color del carbón vegetal será señal de brujería. Igualmente es señal de brujería si en el papel que envuelve el tabaco aparece la figura del paciente clavado un puñal, con una soga amarrada al cuello o aparece la imagen de San Bernardo.

El trago: se procede a limpiar el cuerpo del individuo con varias plantas (ruda, ortiga, guanto) por el espacio de 5 minutos. Una vez terminado esto, se cubre al paciente con una sábana blanca y sopla trago sobre ella; si el individuo ha sido brujeado aparecerá en la sábana la imagen de una cruz de color negro.

El huevo: se limpia al individuo con un huevo ( de gallo y gallina que no haya sido refrigerado) por todo su cuerpo y si, al partir el huevo sobre el agua, este muestra hilos de sangre, la yema está rota o esta "sucio". Igualmente; si el huevo se revienta mientras se limpia al individuo o, al romperlo, despide mal olor es señal de brujería.

\section{Los brujeados}

Durante la investigación, se encontraron varios testimonios de personas que han sido brujeadas y otras que han creído estarlas.

Entre los últimos tenemos el caso de José Ortiz, que fue relatado por Jesús Mancilla, un policía que había seguido su caso (Andrade, 2004: 69). Este hombre, oriundo de Tulcán, había acudido a visitar un curandero a causa de problemas en su salud, para los cuales ningún médico le "atinó", y fue diagnosticado como brujeado. Con ayuda de un policía amigo acudió a la Iglesia a buscar el papel con su nombre; sin embargo, no lo encontró entre los cientos de papeles colocados allí (en los cuales se deseaban los más diversos males: muerte, ruina económica, abandono del esposo, enfermedad de los hijos, etc.) por los brujos, los cuales fueron inmediatamente destruidos por el policía.

Al no encontrar el papel, Don José decayó aún más, adelgazando bastante y presentando cada día nuevos y variados síntomas, por lo que tuvo que ser internado en un hospital donde los médicos veían vanos sus esfuerzos de salvarle la vida. Su amigo decide entonces, en compañía de otros policías, escribir en un papel el nombre de José con la petición de muerte a San Bernardo y colocarlo bajo el santo. Luego acudieron a sacar a José del hospital, dizque a revisar nuevamente si estaba su nombre entre los de los brujeados. Al llegar a la iglesia, claro está que se encontró el papel colocado por los policías, (al cual se habían anexado varios más) lo cual alegra al enfermo y procede a quemarle y a hacerse tres limpias para que en él no queden huellas del mal. Poco tiempo después Don José caminaba por la calle lleno de vida y de salud y, por supuesto, agradecido con los policías que le ayudaron.

Según Lévi-Strauss $(1977,151)$ : “el individuo que en estos casos consiente de ser objeto de un maleficio está íntimamente persuadido por las más solemnes tradiciones de su grupo, de que se encuentra condenado; parientes y amigos comparten esta actitud. El hechizado cede entonces a la acción combinada del fuerte terror que experimenta, del retraimiento súbito y total de los múltiples sistemas de referencia proporcionados por la convivencia del grupo y, finalmente, de la inversión decisiva de estos sistemas que, de individuo vivo, sujeto de derechos y obligaciones, lo proclaman muerto, objeto de temores, ritos y prohibiciones"

Otro caso es relatado por Doña Rosario Calvache, vendedora del mercado, quien nos cuenta que, a finales de los 90’s, su cuñada enfermó gravemente sin que ningún médico le "atinara” el mal que tenía. Es así que deciden acudir donde un conocido curandero de Ilumán, quien, aplicando el diagnóstico con el trago (descrito anteriormente), informa a la mujer que ha sido brujeada y que deberán acudir a la iglesia de Otavalo a retirar la pisada. 
Los familiares de la enferma proceden como les ha indicado el curandero. En la iglesia se entrevistan con el sacristán quien luego de buscar en un cuaderno les informa que efectivamente allí está la pisada. Sin embargo, no les puede entregar “así nomás”, por lo que si desean sacar la pisada deben proceder a pagarle varios millones de sucres, cantidad que no está al alcance de la familia de la víctima. Tal era la angustia que sentían que se obligan a realizar varios préstamos tanto en el banco como con algunos chulqueros para cubrir esa suma, con lo que logran pagar al sacristán y sacar la pisada.

El curandero al abrir la funda con la pisada encuentra una vela casi totalmente consumida y les dice que no puede asegurar salvar a la paciente pues se requieren tres limpias y no va a alcanzar a hacerlas en el poco tiempo de vida que le queda de acuerdo a lo que mostraba la vela. Los familiares insisten hasta que finalmente el curandero accede a realizar las limpias. La paciente acude a realizarse las limpias cada 15 días sintiéndose cada vez un poco mejor. Sin embargo faltando una limpia la paciente encuentra la muerte en un accidente de tránsito. Obra de San Bernardo o no, sus familiares están convencidos que así fue.

Otro testimonio es el de Renata Lara, roquera de la parroquia de San Antonio de Ibarra quien nos relata que compró una imagen de San Bernardo para colocarla en su cuarto como adorno, incluso le cosió un manto negro con dorado "para que se vea bonita". Sin embargo, al poco tiempo de tenerla su familia y ella misma comenzaron a ser víctimas de desgracias e incluso la enfermedad de uno de sus miembros. Deciden entonces acudir donde un curandero quien les dice que el causante de esto es San Bernardo, quien ha decidido tomar la vida de uno de sus miembros debido a que no le guardan el debido respeto y culto. Para que el santo deje de atacarlos deben hacer un círculo de agua bendita en la tierra, en el centro coloquen al santo, ponerle gasolina y prenderle fuego. Angustiados por su situación, siguen los consejos del curandero. Sin embargo mientras se quema el santo parece que sus ojos del santo y sus manos estuvieran atadas. Luego toda la familia se hace tres limpias para librarse del mal ocasionado por la furia del santo, lamentablemente uno de los miembros de la familia fallece a causa de la enfermedad que le aquejaba. La familia piensa que ese fue el pago que tomó el santo por la falta de respeto que le tuvieron.

Varias personas refieren historias parecidas sobre el mal que se ocasiona a través de este santo, lo que cambia son las circunstancias en las que se presenta, así hay caso de matrimonios suspendidos, ganado enfermo, sembríos destruidos por plagas, pero sobre todo muerte.

Cuentan los brujos y curanderos que para brujear a los demás se necesitan ciertas condiciones específicas, así la víctima y su victimario deben encontrarse en igualdad de condiciones; es decir, un empleado no podrá brujear a su jefe, ni se puede brujear a personas de un estrato superior. Sin embargo, hay momentos en que las personas, independientemente de su estatus dentro de la sociedad, se pueden poner "al mismo nivel”; estos momentos son lo que, en el lenguaje de Turner (1977: 54), se conocen como periodos liminales, en el cual el individuo tiene poca o ninguna cualidad de su estado pasado; estos momentos se pueden dar durante una fiesta o cuando se van de copas, pues en estos momentos sus roles sociales desaparecen; también las personas pueden colocarse al mismo nivel por medio de parentesco ritual como es el compadrazgo.

Existen varias historias sobre San Bernardo en la provincia de Imbabura, muchas de las cuales son contadas por personas mayores quienes son los que más conocimiento tienen acerca de este santo. Cuentan que San Bernardo suele aparecerse para llevarse a una persona cuando va a morir y muchos individuos han intentado evitar esto mediante múltiples engaños y otros métodos para evitar que lleve a cabo su misión, dándole regalos o invitándole a comer. En algunas casas, a los niños pequeños se les dice que: “comen como San Bernardo”, porque tiran la comida al piso; como este Santo es un esqueleto, la comida que le brindan queda regada en el suelo y en la silla donde se ha sentado. 


\section{Conclusiones}

Según lo investigado, la brujería no está solamente limitada a los sectores rurales o pobres de la población; esta se da en todos los niveles.

No se han encontrado registros del periodo del origen de este culto en la provincia ni de su relación con el culto a la Santa Muerte o San La Muerte, pero a partir de lo identificado se puede afirmar que se trata del mismo santo que tiene un culto con características propias en la provincia de Imbabura.

La investigación acerca de este santo se lo hizo principalmente entre personas mayores (50 años en adelante) y es muy poco respecto a la riqueza que tenía el culto a este santo hasta mediados del siglo pasado pues las historias que se entretejen en torno a él van desapareciendo de la memoria de la gente, en parte por la persecución de la Iglesia Católica, de la policía y también por el inexorable paso del tiempo, en el cual ciertos cultos dejan de cumplir su función social y pierden vigencia en la vida de los individuos.

El culto a San Bernardo no es conocido en otras provincias del país; sin embargo, en Chimborazo, Cotopaxi y Tungurahua existe un culto similar en la imagen de San Gonzalo. Este santo es muy utilizado por las brujas y brujos de ese sector y, en ocasiones, la policía ha tenido que intervenir para evitar que las comunidades linchen a estas personas a causa de estafas y múltiples males ocasionados. 


\section{Bibliografía}

Andrade, Alfonsina. 2004. Etnomedicina y papel del yachak en las comunidades indígenas y campesinas, Los cayampis de la cuenca sur del Lago San Pablo, Tesis, Quito, PUCE. pp. 173

Araujo Peña, Sandra y otros. 2006. El culto a la Santa Muerte: Un Estudio Descriptivo. Revista de Psicología, Universidad de Londres, http://www.udlondres.com/revista_psicologia/inicio.htm

Evans, Pritchard, E. 1976. Brujería, Oráculos y Magia entre los Azande, Barcelona, Ed. Anagrama.

Fericgla J. 2008, El chamanismo a revisión, Quito, Abya Yala.

Levi-Strauss, C. 1977. Antropología Estructural, Buenos Aires, Ed. Eudeba.

Malinowski B. (s/f). Magia, ciencia y Religión, Barcelona Ed. Planeta Agostini.

Malvido, Elsa. 2005. Crónicas de la Buena Muerte de la Santa Muerte en México, Arqueología Mexicana, Vol. 13 No. 76.

Mazzáfero, V., s/f, Epistemología y Salud Pública, s/ed.

Morales, J. Las Brujas de Mira. En: Mitos y Leyendas del Ecuador, http://www.cuco.com.ar/ecuador1.htm, recuperado el 6 de junio de 2011.

Sharon, D. 1980. El Chamán de los Cuatro vientos, México, Ed. Siglo XXI, pp. 256.

Turner, V. 2005. La Selva de los Símbolos, Madrid, Ed. Siglo XXI, pp. 455. 